\title{
Permeation enhancement effects of leaf materials from different aloe species on in vitro and ex vivo nasal epithelial models
}

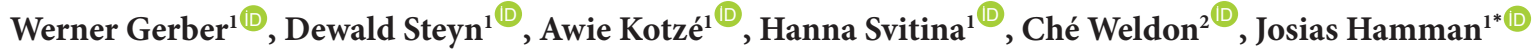 \\ ${ }^{1}$ Centre of Excellence for Pharmaceutical Sciences, Faculty of Health Sciences, North-West University, Potchefstroom, South Africa \\ ${ }^{2}$ Unit for Environmental Sciences and Management, Faculty of Natural Sciences, North-West University, Potchefstroom, South Africa
}

A R T I C L E I N F 0

Article Type:

Original Article

\section{Article History:}

Received: 6 November 2019

Accepted: 1 April 2020

\section{Keywords:}

Aloe

Biological Availability

Herb-Drug Interactions

Intranasal Administration

Medicinal Plants

Tight Junctions

\begin{abstract}
A B S T R A C T
Introduction: The nasal route of drug administration offers an alternative way for oral drug delivery and has the benefit of avoiding first-pass metabolism through drug delivery directly into the systemic circulation. The drug absorption enhancing effects of selected aloe leaf materials have been shown across various delivery routes, but their efficacies in this regard across nasal epithelia have not yet been investigated. The aim of this study was to determine the effects of gel and whole leaf extract materials from three selected aloe species (Aloe vera, Aloe ferox and Aloe muth-muth) on FITC-dextran 4400 permeation across two nasal epithelial models.

Methods: Permeation of FITC-dextran 4400 and histological studies were conducted on both RPMI 2650 cell layers and excised sheep nasal mucosa, while toxicity studies were conducted using a neutral red assay on the RPMI 2650 cell model.

Results: Significantly increased $(P \leq 0.05)$ apparent permeability coefficient $\left(\mathrm{P}_{\text {app }}\right)$ values of FITC-dextran 4400 in the presence of the aloe materials as compared to the control were found with all three aloe species at the highest concentrations (1.5\% and 3\% w/v) in the RPMI 2650 cell line, while only Aloe muth-muth at the highest concentration exhibited significantly $(P \leq$ 0.05) higher $P_{\text {app }}$ values across the excised tissue model. Histological and neutral red analysis showed that Aloe vera materials exhibited detrimental effects, Aloe muth-muth only showed slight effects on cell viability and Aloe ferox exhibited no effect on the nasal epithelium.

Conclusion: This in vitro study showed for the first time the potential of Aloe ferox and Aloe muth-muth leaf materials to enhance nasal drug delivery without causing damaging effects on the epithelium, while Aloe vera enhanced nasal drug delivery with detrimental effects as determined by means of cytotoxicity assays and histological analysis.
\end{abstract}

Implication for health policy/practice/research/medical education:

The gel and whole leaf extract materials of Aloe vera, A. ferox and A. muth-muth are able to increase the permeation of FITCdextran 4400 across the nasal epithelium to different extents and may potentially be used as drug absorption enhancing agents to increase systemic delivery of large molecular weight compounds by the nasal route of drug administration.

Please cite this paper as: Gerber W, Steyn JD, Kotzé AF, Svitina H, Weldon C, Hamman JH. Permeation enhancement effects of leaf materials from different aloe species on in vitro and ex vivo nasal epithelial models. J Herbmed Pharmacol. 2020;9(4):355365. doi: 10.34172/jhp.2020.45.

\section{Introduction}

Pharmacokinetic modulation has been the focus of numerous research studies in recent years, especially research on drug-herb interactions. Substances responsible for the enhancement of pharmacokinetic profiles (i.e. bioenhancers) may be substrates, inhibitors and/or inducers of absorption, metabolism, distribution and excretion (1). Beneficial pharmacokinetic interactions, which may occur at any of these processes, can lead to increased co-administered drug bioavailability. This is especially applicable to drugs with unfavourable physicochemical properties such as large molecular weight drugs that experience difficulty to diffuse across biological membranes, as well as drugs that exhibit a high affinity for efflux transporters or metabolic enzymes. Two medicinal plants with proven drug membrane permeation enhancing 
effects are Aloe vera and A. ferox. The gel and whole leaf extracts of $A$. vera have the ability to open tight junctions between adjacent epithelial cells and thereby increase drug permeation across the intestinal epithelium $(2,3)$, buccal epithelium (4) and the skin $(5,6)$. Furthermore, there is also an indication that p-glycoprotein (P-gp) inhibition takes place in gastro-intestinal epithelium in presence of precipitated polysaccharides from $A$. vera gel $(7,8)$. Permeation enhancement in presence of $A$. ferox leaf materials also took place across the intestinal epithelium (9) and the skin (6), while reduced transepithelial electrical resistance was obtained across excised rat intestinal tissues (10). A plant hybrid called Aloe muthmuth was cultivated through forced pollination between $A$. vera and A. ferox. The current study deployed gel and whole leaf extract from this hybrid, A. muth-muth, in addition to gel and whole leaf materials from $A$. vera and $A$. ferox to investigate the possibility of drug delivery enhancement across the nasal epithelium.

Aloe leaf materials have shown drug absorption enhancement potential across some biological membranes (i.e. intestinal, buccal and skin), but have not yet been evaluated for pharmacokinetic modulation of drug delivery via the nasal route of administration. The nasal route of drug administration provides many advantages over other routes of administration, which may be further optimised by bioenhancers that can facilitate delivery of poorly bioavailable drugs. After nasal administration, drugs are delivered directly into the systemic circulation, thereby circumventing first-pass metabolism. It has a large surface area of approximately $150 \mathrm{~cm}^{2}$ and has a high blood supply along with a leaky epithelial layer (11-13).

The RPMI 2650 cell line is the only indefinitely proliferating human nasal epithelial model currently available, commercially. Although initially regarded to be unsuitable as a transport model when grown under liquid-covered conditions (LCC), further refinement of the growth procedures proved otherwise when the model was grown at the air-liquid interface (ALI). When grown under ALI conditions, the RPMI 2650 cell line presents as a uniform multi-layered cell formation that expresses tight-junctions, multi-drug resistance proteins and transepithelial resistance and permeability values similar to that of excised human nasal mucosa $(11,14-16)$. In contrast to in vitro cell models, excised animal models are much more affordable, relatively uncomplicated to deploy as a transport model and readily accessible. Ex vivo animal models, such as excised sheep nasal mucosa, have been used in nasal delivery studies due to the comparable absorption parameters, relative surface area and mucosal thickness as compared to humans $(17,18)$.

The purpose of this study was to determine if the gel and whole leaf extract materials of selected aloe species namely $A$. vera, $A$. ferox and $A$. muth-muth have any drug permeation enhancement effects across RPMI 2650 nasal epithelial cell layers as well as across excised sheep nasal tissues.

\section{Materials and Methods}

Plant material and extract obtaining

Aloe vera (Aloe barbadensis Mill.) gel and whole leaf extract were donated by Improve USA (De Soto, Texas, USA, authenticated by the International Aloe Science Council). A. ferox Mill. (= Aloe candelabrum A. Berger) gel and de-bittered fibre material were both donated by Organic Aloe (Pty) Ltd (Albertina, South Africa, endorsed by the South African Aloe Council). A. ferox whole leaf extract was constituted by mixing freeze-dried gel:de-bitterd fibre (rind) in a 3:1 ratio (19). Aloe muth-muth (Aloe ferox $x$ vera) leaves were identified and generously provided by botanists Jaap and Hannes Viljoen from Rooiklip Nursery (-34.029293, 20.431906, Swellendam, South Africa) over a period of time and a voucher specimen was deposited at the Mildred van der Merwe herbarium, North-West University, South Africa with accession number PUC0014886 (Collector: JNJ Viljoen 1). The fresh $A$. muth-muth leaves were processed according to a previously published method $(6,20)$. In brief, the thorns were firstly stripped from the leaves. Thereafter, the green rind was separated from the inner pulp and the yellow latex was swiftly rinsed from the gel fillets with distilled water. Both compounds were then finely processed and freeze-dried. The A. muth-muth whole leaf extract was also constituted in a 3:1 gel:rind ratio.

Chemicals and materials

FITC-dextran (MW $=4400$, FD4, Cat. number: 6084246-8), non-essential amino acids (NEAA) (Cat. number: M7145), neutral red (Cat. number: N2889), hematoxylin (Cat. number: GHS132), Eosin Y (Cat. number: HT110216) and Alcian Blue (Cat. number: B8438) were purchased from Sigma-Aldrich (Johannesburg, South Africa). KRB was prepared according to SigmaAldrich's product information sheet (21). RPMI 2650 (nasal septum carcinoma) cells (Lot number: 60525161) were purchased from American Type Culture Collection (Manassas, Virginia, USA). Phosphate buffered saline (PBS) (Cat. number: SH30256.01), Earle's minimum essential media (MEM) (Cat. number: 21090-022), fetal bovine serum (Cat. number: 10270-106), 0.25\% w/v trypsin-EDTA (Cat. number: SV30031.01) were purchased from ThermoFischer (Johannesburg, South Africa) while L-glutamine (Cat. number: G7513) and Pen-Strep (Cat. number: DE17-602E) were purchased from Lonza (Johannesburg, South Africa). ThinCert ${ }^{\mathrm{TM}}$ 12-well plates (Cat. number: 665110) and polyethylene terephthalate coated inserts (Cat. number: 665641) with $0.4 \mu \mathrm{m}$ pore size, $2 \times 10^{6} \mathrm{~cm}^{-2}$ pore density and 1.131 $\mathrm{cm}^{2}$ culture surface were purchased from Greiner BioOne (Frickenhausen, Germany). Sheep nasal tissue was 
sourced from animals slaughtered for meat purposes at a local abattoir (Potchefstroom, South Africa).

\section{${ }^{1} \mathrm{H}-\mathrm{NMR}$ analysis}

Quantitative ${ }^{1} \mathrm{H}-\mathrm{NMR}$ spectroscopic analysis was performed on all the aloe materials investigated in this study to quantify marker molecules including aloverose, glucose, malic acid and lactic acid. A Bruker Avance III HD $500 \mathrm{MHz}$ with automated sample changer and BBFOPLUS SmartProbe was used with nicotinic acid as internal standard according to a previously published method (22).

\section{Fluorescence spectroscopic analysis}

Fluorescence spectroscopic analysis was used to determine the FD4 concentration in the samples obtained from the permeation studies and the analyses were done using a Spectramax Paradigm ${ }^{\circledR}$ (San Jose, California, USA, Serial nr: 33270-1142) multi-mode detection platform plate reader. FD4 was analyzed with excitation and emission wavelengths set at $485 \mathrm{~nm}$ and $525 \mathrm{~nm}$, respectively $(13,23)$. The fluorescence spectroscopic analysis method for FD4 was validated in terms of linearity, accuracy, precision, limit of detection and limit of quantification.

\section{RPMI 2650 cell culturing}

RPMI 2650 cells were initially cultured in $75 \mathrm{~cm}^{2}$ culture flasks with MEM fortified with 10\% FBS, 1\% NEAA, 100 U/ $\mathrm{mL}$ penicillin, $100 \mathrm{U} / \mathrm{mL}$ streptomycin, $2 \mathrm{mM} \mathrm{L}$-glutamine. As soon as confluency of approximately $90 \%$ was reached, the flasks were washed twice with $10 \mathrm{ml}$ PBS before being trypsinized in an incubator for 5 minutes with $0.25 \%$ $(\mathrm{w} / \mathrm{v})$ trypsin-EDTA. Following trypsinization, the cells were counted using a haemocytometer and seeded on the apical side of the 12 -well plate membranes (ThinCert ${ }^{\mathrm{TM}}$ ) at a density of $6 \times 10^{5}$ cells $/ \mathrm{cm}^{2}$. All cells used for seeding were between passages 25 and 47 .

Following seeding of the cells into the 12 -well plates, the cells were cultured for 2 days under LCC conditions and then cultured for a further 19 days at the ALI. During the first 2 days, LCC conditions included adding 0.8 $\mathrm{mL}$ growth medium to the apical side and $4 \mathrm{~mL}$ growth medium to the basolateral side. After 2 days, the growth medium on the apical side was removed by aspiration, while the medium changes on the basolateral side continued every second day. Following the ALI growth phase, the inserts with the cell layers were transferred to 12 -well transport plates in which the permeation studies were conducted.

All the cell flasks and plates were kept in an incubator at $37^{\circ} \mathrm{C}$ humidified atmosphere containing $5 \% \quad \mathrm{CO}_{2}$ throughout the cell culturing period, while media was changed every second day $(11,15,24)$.

Sheep nasal mucosa excision

Immediately following slaughter of a sheep, the snout of the animal was removed by a cross sectional incision just anterior to the eyes. The skin was removed and the tissue sample was rinsed, submerged and transported to the laboratory using ice-cold KRB. The snout was bisected via a vertical, longitudinal incision along the septal midline. The septum was completely removed and discarded. From each half, the conchae were isolated by a vertical incision through the lateral wall of the nasal cavity, just posterior to the Incisura nasoincisiva. The epithelial tissue sheets were then removed from the surface of the cartilage via blunt dissection. Strips of approximately $1 \mathrm{~cm}$ in width were cut from the nasal epithelial tissue sheets and mounted in Sweetana-Grass diffusion chambers for permeation studies $(17,25-27)$.

Permeation studies

In both models (i.e. RPMI 2650 cells at ALI and excised sheep nasal tissue), FD4 $(500 \mu \mathrm{g} / \mathrm{mL})$ dissolved in KRB was used as a marker molecule for paracellular transport. Permeation studies were done in the absorptive direction only (i.e. unidirectional). During the FD4 absorptive permeation studies in the RPMI 2650 cell model, 0.8 $\mathrm{mL}$ of marker compound solution (in the presence and absence of different aloe materials) was added to the apical side of the membrane and $1.8 \mathrm{~mL} \mathrm{KRB}$ was added to the basolateral side. In the excised tissue model, the same method was followed, but volumes of $7 \mathrm{~mL}$ were used in both the apical and basolateral chambers.

The RPMI 2650 cell layers $\left(37^{\circ} \mathrm{C}\right)$ and the excised nasal epithelial tissues $\left(34^{\circ} \mathrm{C}\right)$ were acclimatised in preheated KRB for 15 minutes before permeation studies commenced. All aloe gel and whole leaf extracts were tested in experimental solutions at concentrations of 0.5 , 1.5 and $3 \% \mathrm{w} / \mathrm{v}$, respectively in triplicate. Following the application of the experimental solutions to the donor chambers, the samples $(180 \mu \mathrm{L})$ were withdrawn from the acceptor chambers at time intervals of $5,10,15,30,60$, 90, 120 and 180 minutes, replaced with equal volumes of pre-heated KRB and analysed for the presence of marker compound using fluorescent spectroscopy as described above.

\section{Data analysis}

Following fluorescence spectroscopic analysis of the samples obtained from the permeation studies, the data were corrected for dilution and the percentage transport for each experimental solution was calculated (28) with equation 1 .

Transport $=\frac{\text { Concentration at specific time }}{\text { Concentration of donor solution }} \times 100$

The apparent permeability $\left(\mathrm{P}_{\text {app }}\right)$ coefficient values of each marker compound were calculated using equation 2 $(11,28,29)$.

$$
P_{a p p}=\frac{d Q}{d t}\left(\frac{1}{A \cdot 60 \cdot C_{0}}\right)
$$


Where $\mathrm{P}_{\text {app }}$ is the apparent permeability coefficient $\left(\mathrm{cm} \cdot \mathrm{s}^{-1}\right)$, is the permeability rate per minute, $\mathrm{A}$ is the diffusion area of the membrane $\left(\mathrm{cm}^{2}\right)$ and $\mathrm{C}_{0}$ is the initial concentration of each marker compound used.

In vitro cytotoxicity and histology

Neutral red viability assay

Cell viability of the RPMI 2650 cells when exposed to the aloe materials investigated in this study was determined using a neutral red assay. RPMI 2650 cells were seeded at 250000 cells $/ \mathrm{cm}^{2}$ in 96 well-plates. After a 24-hour recovery period allowing cells to attach to the plates and reach confluency of $80 \%$, the cells were treated with different aloe materials at a range of concentrations $(0.25$ to $6 \% \mathrm{w} / \mathrm{v}$ ) in $\mathrm{KRB}$ with $10 \%$ FBS supplementation for 3 hours. Since many plant extracts contain compounds with intrinsic reductive potential such as antioxidants, the neutral red assay was performed instead of the 3-(4,5-dimethylthiazol-2-yl)-2,5-diphenyltetrazolium bromide (MTT) cytotoxicity assay to avoid false positive results (30).

For the neutral red assay, the aloe material containing experimental solutions were removed after the 3-hour exposure time and the cells were washed three times with $200 \mu \mathrm{L}$ KRB. Following the washing step, a volume of $100 \mu \mathrm{L}$ of a $0.033 \%$ neutral red solution in KRB was added to each well and the plate was placed back in the incubator. After a further 2 hours of incubation, the medium was removed and the cells were washed with $100 \mu \mathrm{L}$ of a fixation solution ( $1 \% \mathrm{CaCl}_{2}$ in $0.5 \%$ formaldehyde). Then, a volume of 150 $\mu \mathrm{L}$ of a $1 \% \mathrm{v} / \mathrm{v}$ acetic acid in $50 \% \mathrm{v} / \mathrm{v}$ ethanol solution was added to each well for the solubilisation of the neutral red dye. The plates were protected from light and gently shaken for 10 minutes for complete dissolution of the dye. The neutral red absorbance of each well treated with aloe was measured at $540 \mathrm{~nm}$ with a SpectraMax ${ }^{\circledR}$ plate reader, after which the background noise was subtracted following measurement at a wavelength of $690 \mathrm{~nm}$. The percentage cell viability was determined using Equation 3.

\section{Histology}

Histological analysis of the RPMI 2650 cell layers and excised nasal epithelial tissues after exposure to the highest concentration (i.e. $3 \% \mathrm{w} / \mathrm{v}$ ) aloe materials investigated in this study, were conducted. Excised sheep nasal tissue samples before the permeation study (intact control) and samples at the end of each 3 hours permeation study with $3 \%(\mathrm{w} / \mathrm{v})$ of each aloe material were fixated in $10 \%$ buffered formalin at $4^{\circ} \mathrm{C}$ for 24 hours. RPMI 2650 cell layers before the permeation study (intact control) and at the end of each 3 hours permeation study with $3 \%(\mathrm{w} / \mathrm{v})$ aloe materials were washed with PBS and fixated in 10\% buffered formalin at room temperature for 1 hour. The tissue and cell samples were subsequently dehydrated in a graded series of ethanol solutions and thereafter embedded in paraffin wax. Embedded samples were sliced into 4-5 $\mu \mathrm{m}$ sections that were stained with hematoxylineosin and 1\% Alcian Blue. After staining, the sections were examined under a Nikon E800 compound microscope using the $60 \times$ objective. The sheep nasal epithelium and RPMI 2650 cells' height and nuclei area in the cells were measured from five different slices per sample using NISElements, version 4.05 software.

\section{Viscosity}

The viscosity of all the aloe experimental solutions (including the gel and whole-leaf extract materials of all the selected species) was determined at three concentrations (i.e. $0.5,1.5$ and $3 \% \mathrm{w} / \mathrm{v}$ ) using a TA Instruments ARES-G2 (New Castle, Delaware, USA, Serial number: 4010-0677) viscometer. A stainless steel $40 \mathrm{~mm}$ parallel plate geometry was used with gap width set at $1 \mathrm{~mm}$. These parameters resulted in the use of a minimum volume of $1.26 \mathrm{~mL}$ sample. An oscillatory mode was used at $37^{\circ} \mathrm{C}$ with the logarithmic shear rate ranging from 10 to $100 \mathrm{rad} / \mathrm{s}$ (12). With pseudoplastic flow, the rheogram follows a straight line at higher shear rates, thus a minimum viscosity value can be attained from the slope of the straight line between 0 and $5 \mathrm{rad} / \mathrm{s}\left(\mathrm{r}^{2} \geq 0.990\right)$ on the graph (31).

Statistical analysis

Statistical data analysis of the $\mathrm{P}_{\text {app }}$ values and histological parameters for all test groups in both models was performed with software from RStudio: Integrated development environment for $\mathrm{R}$ (version 1.1.453) software (RStudio, Inc., Boston, MA). The analysis was done by means of non-parametric Kruskal-Wallis test followed by Dunn's post-hoc test for comparison of multiple groups. Differences were considered statistically significant when $P<0.05$.

\section{Results}

${ }^{1} \mathrm{H}-\mathrm{NMR}$ analysis results

The chemical composition of the A. muth-muth gel and whole leaf extracts in terms of quantities (\% dry weight) of selected marker compounds obtained from quantitative ${ }^{1} \mathrm{H}$-NMR analysis are summarized in Table 1 . The chemical composition of the A. ferox and A. vera gel and whole leaf extracts as determined by the same quantitative ${ }^{1} \mathrm{H}-\mathrm{NMR}$ analysis method have already been published previously $(6,10)$.

The A. muth-muth gel material contained all the marker compounds (i.e. aloverose, glucose and malic acid) commonly used for the identification of $A$. vera gel material. Aloverose (also known as acetylated polymannose or acemannan) is one of the major bioactive compounds in $A$. vera responsible for certain medicinal properties of this plant $(10,32)$. The aloverose and malic acid contents were found to be similar in A. muth-muth 
gel compared to that in $A$. vera gel ( $10.4 \%$ vs $12.7 \%$ for aloverose and $18.3 \%$ vs $20.0 \%$ for malic acid, respectively). Interestingly, the whole-leaf material extract of $A$. muthmuth contained higher quantities of aloverose and malic acid than $A$. vera whole leaf extract $(9.3 \%$ vs $5.5 \%$ for aloverose and $16 \%$ vs $1.2 \%$ for malic acid) $(2,10)$.

\section{Fluorescence spectroscopic verification}

All the validation results are summarized in Table 2 and this analytical method complied with the limits set for the different validation parameters.

Permeation studies

FITC-dextran permeation across RPMI 2650 nasal epithelial cell layers

The apparent permeability coefficient $\left(\mathrm{P}_{\text {app }}\right)$ values of FD4 in the absence (control) and in the presence of three concentrations $(0.5 \%, 1.5 \%$ and $3 \% \mathrm{w} / \mathrm{v})$ of the selected aloe gel materials across RPMI 2650 nasal epithelial cell layers are shown in Figure 1.

Aloe vera gel increased FD4 permeation across the RPMI 2650 cell layers at all three concentrations tested, with the two highest concentrations' permeation being statistically significantly $(P<0.05)$ higher than that of the control. However, it is simultaneously found that the permeation of FD4 in the presence of $3 \% \mathrm{w} / \mathrm{v}$ A. vera gel is slightly lower than that of the $1.5 \% \mathrm{w} / \mathrm{v}$ concentration. A. ferox gel mediated a slight increase in FD4 permeation across the RPMI 2650 cell layers, presenting with an inverse-bell curve across the concentration range. However, only the $3 \% \mathrm{w} / \mathrm{v}$ suspension indicated a statistically significant increase in permeation. A. muth-muth gel caused a pronounced increase in FD4 permeation across the

Table 1. Percentage content of selected marker molecules in Aloe muthmuth gel and whole leaf extracts as determined by ${ }^{1} \mathrm{H}-\mathrm{NMR}$ spectroscopy

\begin{tabular}{lcc}
\hline Marker compound & $\begin{array}{c}\text { A. muth-muth } \\
\text { gel (\%) }\end{array}$ & $\begin{array}{c}\text { A. muth-muth whole- } \\
\text { leaf extract (\%) }\end{array}$ \\
\hline Aloverose & 10.4 & 9.3 \\
Glucose & 9.1 & 8.4 \\
Malic acid & 18.3 & 16 \\
Citric acid & Not detected & 2.2 \\
Whole leaf marker & Not detected & 3.0 \\
\hline
\end{tabular}

Table 2. Fluorescent spectroscopic validation results for FITC-dextran 4400 (FD4)

\begin{tabular}{llll}
\hline Linearity $\left(\mathbf{R}^{2}\right)$ & 0.999 & & \\
\hline Limit of detection $(\mu \mathrm{g} / \mathrm{mL})$ & 0.005 & & \\
\hline Limit of quantification $(\mu \mathrm{g} / \mathrm{mL})$ & 0.016 & & \\
\hline Concentration FD4 & $125 \mu \mathrm{g} / \mathrm{mL}$ & $62.5 \mu \mathrm{g} / \mathrm{mL}$ & $12.5 \mu \mathrm{g} / \mathrm{mL}$ \\
\hline Accuracy (\%) & 95.77 & 98.49 & 104.67 \\
\hline Intra-day precision (\% RSD) & 2.77 & 2.75 & 2.53 \\
\hline Inter-day precision (\% RSD) & 2.89 & 3.08 & 2.51 \\
\hline
\end{tabular}

RPMI 2650 nasal epithelial cell layers in a concentration dependent manner and the highest concentration $(3 \%$ $\mathrm{w} / \mathrm{v}$ ) applied caused a statistically significant increase in the $\mathrm{P}_{\text {app }}$ of FD4, which was also much higher than those of $A$. ferox and $A$. vera gel.

The $\mathrm{P}_{\text {app }}$ values of FD4 in the presence of three concentrations $(0.5 \%, 1.5 \%$ and $3 \% \mathrm{w} / \mathrm{v})$ of the selected aloe whole leaf extracts are shown in Figure 2.

Both $A$. vera and $A$. muth-muth whole leaf extract mediated a concentration dependent increase in FD4 permeation across the RPMI 2650 nasal epithelial cell layers, with both species causing a statistically significant difference in FD4 $\mathrm{P}_{\text {app }}$ values from that of the control $(P<$ $0.05)$ at the two highest concentrations applied (1.5\% and $3 \% \mathrm{w} / \mathrm{v})$. Interestingly, $A$. ferox whole leaf extract indicated that statistically significant increases in permeation were found at the lowest and highest concentrations, presenting an inverse bell-shaped permeation pattern similar to that found with the A. ferox gel material.

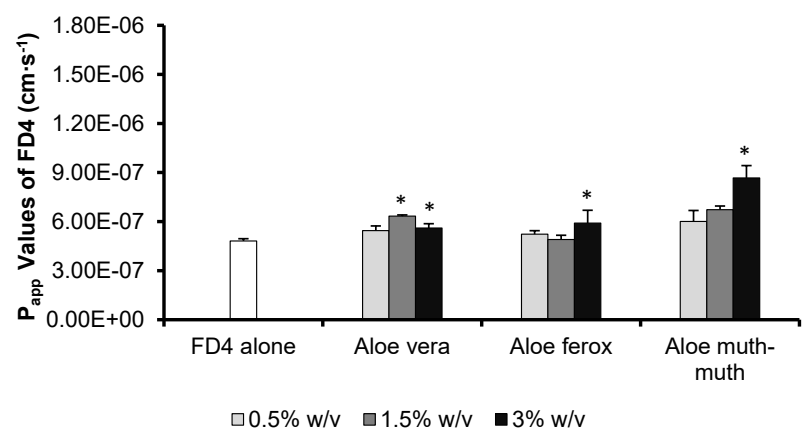

Figure 1. Apparent permeability coefficient $\left(\mathrm{P}_{\text {app }}\right)$ values of FITC-dextran 4400 (FD4) alone (control) and in the presence of different concentrations of Aloe vera, A. ferox and A. muth-muth gel across RPMI 2650 nasal epithelial cell layers in the absorptive direction ( ${ }^{*}$ indicates $P \leq 0.05$ compared to FD4 alone, Kruskal-Wallis tests followed by Dunn's post hoc test).

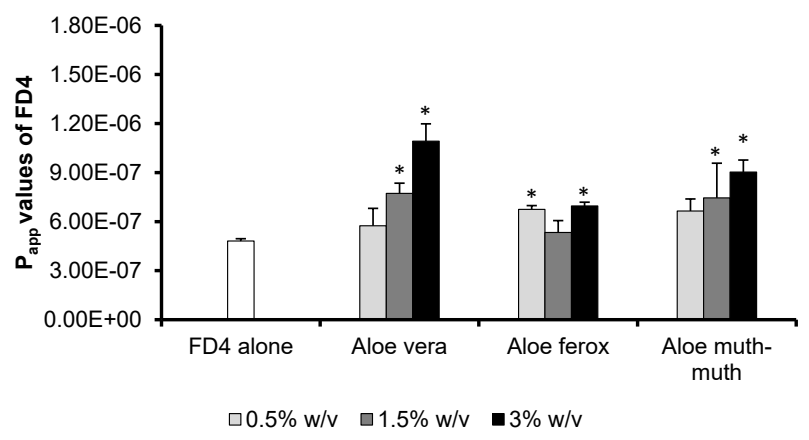

Figure 2. Apparent permeability coefficient $\left(\mathrm{P}_{\text {app }}\right)$ values of FITC-dextran (FD4) alone (control) and in the presence of different concentrations of Aloe vera, A. ferox and A. muth-muth whole leaf extract across RPMI 2650 nasal epithelial cell layers in the absorptive direction ( ${ }^{*}$ indicates $P$ $\leq 0.05$ compared to FD4 alone, Kruskal-Wallis tests followed by Dunn's post-hoc test). 
FITC-dextran permeation across excised sheep nasal epithelial tissues

The $\mathrm{P}_{\text {app }}$ values of FD4 in the absence (control) and in the presence of three concentrations $(0.5 \%, 1.5 \%$ and $3 \%$ $\mathrm{w} / \mathrm{v}$ ) of the selected aloe gel materials across excised sheep nasal epithelial tissues are shown in Figure 3, while the $\mathrm{P}_{\text {app }}$ values of FD4 in the presence of three concentrations $(0.5 \%, 1.5 \%$ and $3 \% \mathrm{w} / \mathrm{v})$ of the selected aloe whole leaf extract are shown in Figure 4.

In Figure 3 one can see that $A$. vera gel caused a more pronounced increase in FD4 permeation across excised sheep nasal mucosa as compared to the RPMI 2650 cell model. In this excised tissue model, a concentration dependent increase is apparent. The A. ferox gel showed a permeation enhancement effect on FD4 in the same inverse bell-shaped curve as found with the RPMI 2650 cell model, although in the excised tissue model no statistical significant differences were found. The A. muthmuth gel exhibited a concentration dependent increase in FD4 permeation across the excised sheep nasal epithelial tissue similar to the results obtained in the RPMI 2650 cell layer model.

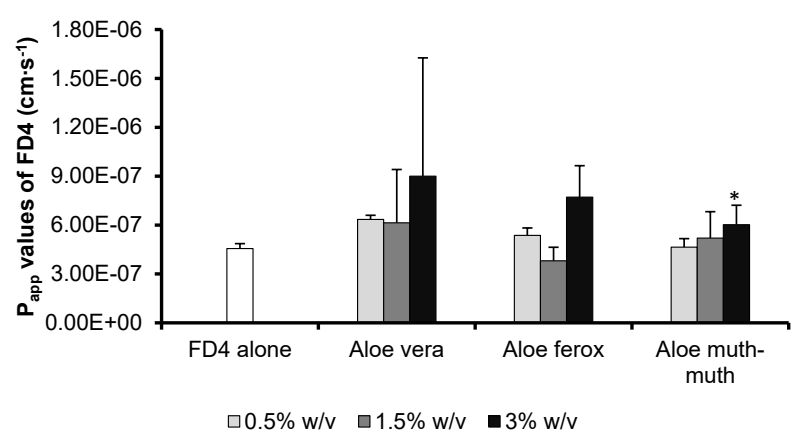

Figure 3. Apparent permeability coefficient $\left(\mathrm{P}_{\text {apo }}\right)$ values of FITC-dextran (FD4) alone (control) and in the presence of different concentrations of Aloe vera, A. ferox and $A$. muth-muth gel across excised sheep nasal epithelial tissues in the absorptive direction (* indicates $P \leq 0.05$ compared to FD4 alone, Kruskal-Wallis tests followed by Dunn's post hoc test)

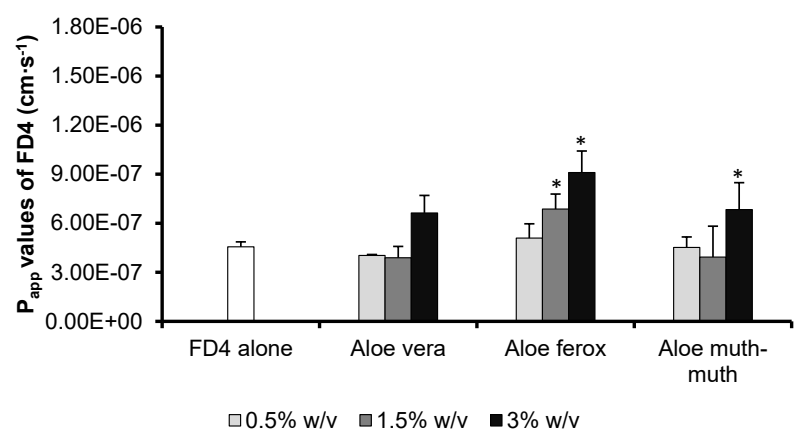

Figure 4. Apparent permeability coefficient $\left(\mathrm{P}_{\text {app }}\right)$ values of FITC-dextran (FD4) alone (control) and in the presence of different concentrations of Aloe vera, $A$. ferox and $A$. muth-muth whole leaf extract across excised sheep nasal epithelial tissue in the absorptive direction (* indicates $P \leq$ 0.05 compared to FD4 alone, Kruskal-Wallis tests followed by Dunn's post-hoc test)
In general, the whole leaf extracts from all three aloe species investigated in this study caused an increase in FD4 permeation across the excised sheep nasal epithelial tissues in a concentration dependent manner. In addition, similar trends in absorption enhancement are seen in Figure 4 for $A$. vera and A. muth-muth than was seen in the RPMI 2650 cell model (Figure 2). However, with the excised sheep nasal mucosa model only A. ferox at the two highest concentrations and $A$. muth-muth at the highest concentration presented with statistically significant increases in FD4 permeation when compared to that of the control.

\section{In vitro cytotoxicity}

Aloe vera gel and whole leaf extract

The percentage cell viability of RPMI 2650 cells after exposure to A. vera gel and whole leaf extract as a function of concentration is shown in Figure 5.

According to a previously published classification system, a substance can be considered as non-cytotoxic if cell viability remains above $80 \%$, weakly-cytotoxic if cell viability ranges from $60 \%$ to $80 \%$, moderately cytotoxic between $40 \%$ and $60 \%$ and strong or severe cytotoxicity is indicated by cell viability below $40 \%$ (34). Figure 5 indicates that $A$. vera gel was weak to moderate cytotoxic at concentrations up to $1 \% \mathrm{w} / \mathrm{v}$ and severely cytotoxic at concentrations higher than $2 \% \mathrm{w} / \mathrm{v}$, while $A$. vera whole leaf extract was non-cytotoxic up to concentrations of $1 \%$ $\mathrm{w} / \mathrm{v}$ and only moderately cytotoxic up to a concentration of $3 \% \mathrm{w} / \mathrm{v}$.

\section{Aloe ferox gel and whole leaf extract}

The percentage cell viability of RPMI 2650 cells after exposure to $A$. ferox gel and whole leaf extract as a function of concentration is shown in Figure 6.

A. ferox gel showed no to weak cytotoxic effects for all the concentrations tested (i.e. up to $6 \% \mathrm{w} / \mathrm{v}$, Figure 6), whereas $A$. ferox whole leaf extract exhibited no to weak cytotoxicity up to a concentration of $4 \% \mathrm{w} / \mathrm{v}$ and moderate cytotoxic effects at concentrations between 5 and $6 \% \mathrm{w} / \mathrm{v}$.

Aloe muth-muth gel and whole leaf extract

The percentage cell viability of RPMI 2650 cells after (a)

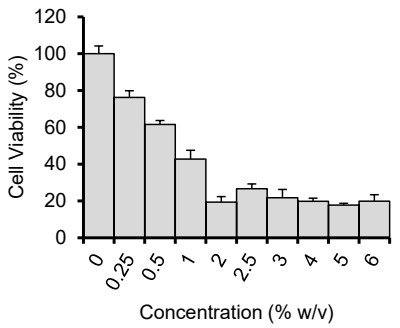

(b)

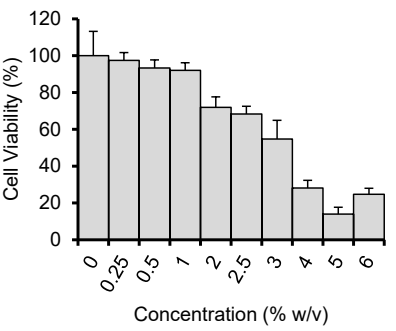

Figure 5. Percentage cell viability as determined with a neutral red assay on RPMI 2650 cells after 3 hours exposure to a range of Aloe vera gel (a) and whole leaf extract (b) concentrations 
(a)

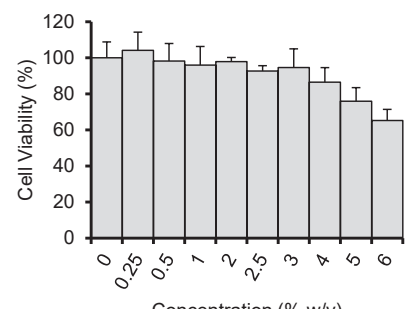

Concentration $(\% \mathrm{w} / \mathrm{v})$

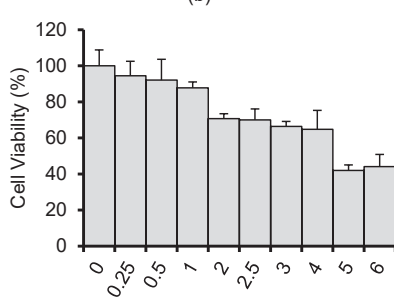

Concentration $(\% \mathrm{w} / \mathrm{v})$

Figure 6. Percentage cell viability as determined with a neutral red assay on RPMI 2650 cells after 3 hours exposure to a range of Aloe ferox gel (a) and whole leaf extract (b) concentrations

(a)

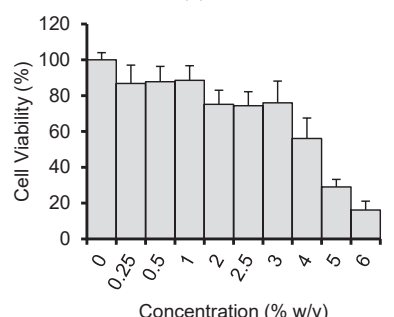

Figure 7. Percentage cell viability as determined with a neutral red assay on RPMI 2650 cells after 3 hours exposure to a range of Aloe muth-muth gel (a) and whole leaf extract (b) concentrations

exposure to A. muth-muth gel and whole leaf extract as a function of concentration is shown in Figure 7.

A. muth-muth gel showed no cytotoxic effects up to $1 \%$ $\mathrm{w} / \mathrm{v}$, moderately cytotoxic effects up to $4 \% \mathrm{w} / \mathrm{v}$ and was strongly cytotoxic at 5 and $6 \% \mathrm{w} / \mathrm{v}$ (Figure 7). A. muthmuth whole leaf extract was only moderately cytotoxic up to the highest concentration tested, namely $6 \% \mathrm{w} / \mathrm{v}$.

\section{Histology}

Histological analyses of the RPMI 2650 cell layers as well as the excised sheep nasal epithelial tissues were conducted in the absence and presence of the selected aloe materials and the micrographs are shown in Figures 8 and 9, respectively. Histological parameters of the RPMI 2650 cell layers as well as excised nasal epithelial tissues are shown in Table 3.

From Figure 8, it is clear that the RPMI 2650 cells cultured under ALI conditions developed multi-layered epithelia on the insert support filter membranes without differentiation into different types of cells as visible in the excised sheep nasal epithelial tissue (Figure 9). Morphological changes, which may indicate cell damage, can be observed on the micrographs of the RPMI 2650 cell layers exposed to A. vera gel and whole leaf extract. Sinusoidal gaps appeared within the RPMI 2650 cell layer after treatment with $A$. vera gel and whole leaf extract. The RPMI 2650 cell layer thickness was not changed after treatment with $A$. vera whole leaf extract, but it increased $(P<0.01)$ after treatment with $A$. vera gel. On the other hand, the excised sheep nasal epithelial tissue that was exposed to $A$. vera gel exhibited a reduction in thickness (Table 2). This may be explained by the differences in the morphology of the two models, whereby excised sheep nasal epithelial tissue consists of a pseudostratified monolayer, while the multi layered in vitro RPMI 2650 cell model provides a network of cells that collectively allow some adhesion for detached cells and thereby expands the overall thickness of the cell layers. The widening of intercellular spaces was characteristic of cell layers exposed to both A. muth-muth whole leaf extract and gel, but without concurrent increase of epithelial thickness. A slight reduction in epithelial thickness was observed after treatment with A. ferox whole leaf extract. The RPMI 2650 cell layers exposed to Krebs-Ringer Bicarbonate buffer (KRB) and A. ferox gel were morphologically comparable with that of the intact control without any signs of cell disruption.

The excised sheep nasal epithelial tissues consist of

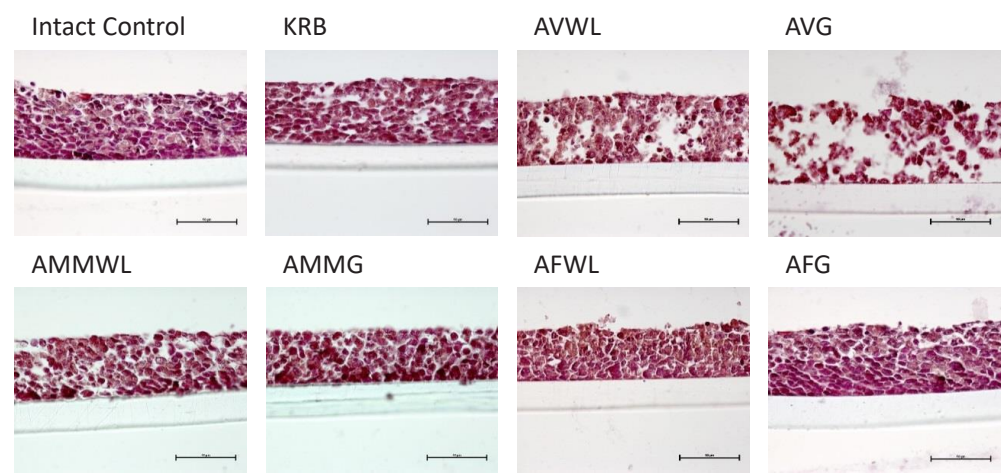

Figure 8. Representative micrographs of RPMI 2650 cell layers grown with the air-liquid interface technique before and after 180 min exposures in the permeability study. Intact Control: RPMI 2650 cell layer before the permeation experiment started. KRB: after exposure to Krebs-Ringer Bicarbonate buffer only. AVWL: after exposure to $3 \% \mathrm{w} / \mathrm{v} A$. vera whole leaf extract. AVG: after exposure to $3 \% \mathrm{w} / \mathrm{v} A$. vera gel. AMMWL: after exposure to $3 \% \mathrm{w} / \mathrm{v} A$. $m$ muthmuth whole leaf extract. AMMG: after exposure to $3 \%$ w/v Aloe muth-muth gel. AFWL: after exposure to $3 \%$ w/v Aloe ferox whole leaf extract. AFG: after exposure to $3 \% \mathrm{w} / \mathrm{v}$ Aloe ferox gel. Scale bar $=50 \mu \mathrm{m}$ 


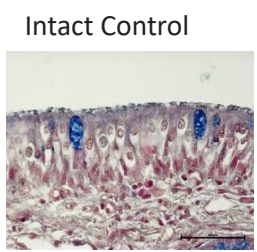

AMMWL

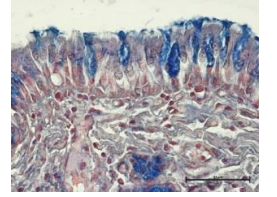

KRB

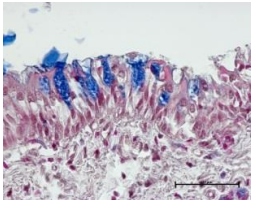

AMMG

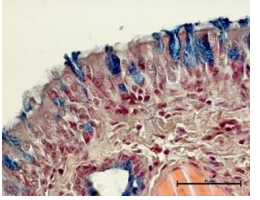

AVWL

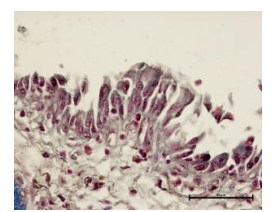

AFWL

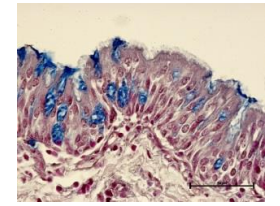

AVG

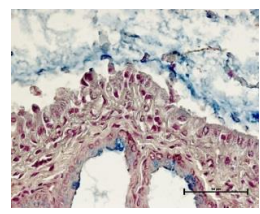

AFG

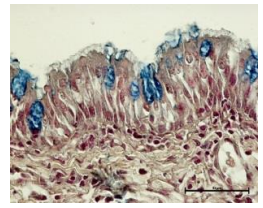

Figure 9. Representative micrographs of excised sheep nasal mucosa before and after 180 min exposures in the permeability study. Intact control: Excised sheep nasal mucosa before the permeation experiment started. KRB: after exposure to Krebs-Ringer Bicarbonate buffer only. AVWL: after exposure to $3 \% \mathrm{w} / \mathrm{v}$ A. vera whole leaf extract. AVG: after exposure to $3 \% \mathrm{w} / \mathrm{v} A$. vera gel. AMMWL: after exposure to $3 \%$ w/v $A$. muth-muth whole leaf extract. AMMG: after exposure to $3 \% \mathrm{w} / \mathrm{v}$ Aloe muth-muth gel. AFWL: after exposure to $3 \% \mathrm{w} / \mathrm{v}$ Aloe ferox whole leaf extract. AFG: after exposure to $3 \%$ w/v Aloe ferox gel. Scale bar $=50 \mu \mathrm{m}$.

pseudostratified ciliated columnar epithelial cells with interspaced mucus producing goblet cells (Figure 9). There is no visible sign of tissue alteration of the excised nasal epithelial tissues after exposure to KRB, A. ferox gel and whole leaf extract, A. muth-muth gel and whole leaf extract when compared to the intact control group. However, the excised epithelial tissue exposed to $A$. vera whole leaf extract has a heterogeneous appearance consisting of some loosely connected as well as detached epithelial cells. This effect was even more pronounced after exposure to $A$. vera gel with only the germ layer of the epithelial cells remaining intact. The epithelial thickness and average epitheliocyte nucleus area were significantly reduced $(P<0.001)$ compared to the control group (Table 3 ) after exposure to the $A$. vera gel and whole leaf extract materials.

\section{Viscosity}

All of the tested aloe materials exhibited pseudoplastic flow behaviour in both the gel and whole leaf extract form, which was expected of aqueous suspensions of natural hydrocolloids (31). The viscosity values of the selected aloe gel and whole leaf extracts in the state that it was used are shown in Table 4.

The viscosity values in Table 4 indicate that there is a dramatic increase in viscosity with an increase in concentration of the $A$. vera gel, $A$. ferox whole leaf extract and A. muth-muth gel and whole leaf extracts. Viscosity of $A$. vera whole leaf extract and $A$. ferox gel remained relatively low over all three concentrations, while the viscosity of the solvent (i.e. KRB) remained virtually undetected under the experimental parameters.

\section{Discussion}

Although a slight decreased FD4 $\mathrm{P}_{\text {app }}$ value was found at the highest concentration of $A$. vera gel (i.e. at 3.0\% $\mathrm{w} / \mathrm{v}$ ) compared to that of the $1.5 \% \mathrm{w} / \mathrm{v}$ concentration during permeation across the RPMI 2650 cell layers, the permeation trends are generally in coherence with previous results where $A$. vera gel increased the transport of different molecules in a concentration dependent manner across other epithelial membranes including intestinal and buccal mucosal surfaces $(2,4)$. The slight decrease in FD4 permeation across the RPMI 2650 nasal epithelial cell

Table 3. Parameters of epithelia of two different nasal tissue models

\begin{tabular}{|c|c|c|c|c|}
\hline \multirow[b]{2}{*}{ Experimental group } & \multicolumn{2}{|c|}{ Excised sheep tissue } & \multicolumn{2}{|c|}{ RPMI 2650 cell line } \\
\hline & $\begin{array}{l}\text { Epithelia thickness } \\
\qquad(\mu \mathrm{m})\end{array}$ & $\begin{array}{c}\text { Average epitheliocyte's } \\
\text { nucleus area }\left(\mu \mathrm{m}^{2}\right)\end{array}$ & $\begin{array}{l}\text { Epithelia thickness } \\
\qquad(\mu \mathrm{m})\end{array}$ & $\begin{array}{c}\text { Average epitheliocyte } \\
\text { nuclei area, }\left(\mu \mathrm{m}^{2}\right)\end{array}$ \\
\hline Intact control & $52.9 \pm 4.4$ & $36.1 \pm 6.6$ & $53.3 \pm 8.1$ & $14.3 \pm 7.2$ \\
\hline A. vera gel $3 \%$ & $31.1 \pm 20.2 * * *$ & $24.0 \pm 8.5 * * *$ & $61.6 \pm 10.6^{* *}$ & $13.3 \pm 5.7$ \\
\hline A. vera whole leaf extract $3 \%$ & $32.8 \pm 15.8 * * *$ & $18.2 \pm 6.8 * * *$ & $50.1 \pm 3.1$ & $15.9 \pm 5.6$ \\
\hline A. ferox gel $3 \%$ & $51.3 \pm 15.3$ & $36.2 \pm 7.2$ & $54.2 \pm 9.9$ & $15.2 \pm 4.6$ \\
\hline A. ferox whole leaf extract $3 \%$ & $55.4 \pm 8.3$ & $31.7 \pm 7.6$ & $47.6 \pm 4.6 *$ & $15.9 \pm 5.2$ \\
\hline A. muth-muth gel $3 \%$ & $48.0 \pm 11.6$ & $34.2 \pm 8.8$ & $53.4 \pm 5.1$ & $15.7 \pm 5.1$ \\
\hline A. muth-muth whole leaf extract $3 \%$ & $47.1 \pm 9.7$ & $36.0 \pm 10.9$ & $51.1 \pm 6.2$ & $15.4 \pm 5.4$ \\
\hline
\end{tabular}

Data represented as mean \pm SD, Kruskal-Wallis test followed by Dunn's post hoc test. $* P<0.05, * * P<0.01, * * * P<0.001$, which indicates statistically significantly differences between the experimental groups (exposed to different Aloe materials) and the intact control group (not exposed to Aloe material). 
Table 4. Viscosities $\left(\mathrm{Pa}^{-1} \mathrm{~s}^{-1}\right)$ of the selected aloe gel and whole leaf extracts at different concentrations in Krebs-Ringer Bicarbonate buffer

\begin{tabular}{|c|c|c|c|c|}
\hline \multirow{2}{*}{ Experimental groups } & & \multicolumn{3}{|c|}{ Concentration } \\
\hline & & $0.5 \% \mathrm{w} / \mathrm{v}$ & $1.5 \% \mathrm{w} / \mathrm{v}$ & $3 \% \mathrm{w} / \mathrm{v}$ \\
\hline \multirow{7}{*}{ Viscosity $\left(\times 10^{-3} \mathrm{~Pa} \cdot \mathrm{s}^{-1}\right)$} & A. vera gel & 1.83 & 5.57 & 18.09 \\
\hline & A. vera whole leaf extract & 0.56 & 1.12 & 1.69 \\
\hline & A. ferox gel & 1.16 & 0.96 & 1.17 \\
\hline & A. ferox whole leaf extract & 0.83 & 1.73 & 6.03 \\
\hline & A. muth-muth gel & 3.43 & 4.29 & 14.17 \\
\hline & A. muth-muth whole leaf extract & 5.32 & 3.92 & 13.11 \\
\hline & KRB & \multicolumn{3}{|c|}{0.00} \\
\hline
\end{tabular}

layers observed at the highest concentration of $A$. vera gel can possibly be explained by the relatively high viscosity of the A. vera gel at this concentration. The relatively high viscosity at the highest $A$. vera gel concentration has probably hampered FD4 diffusion. Previous findings also supported this explanation, since decreased percentage ketoprofen permeation across a synthetic membrane was evident with an increase in $A$. vera gel concentration (6). Another potential reason for decreased FD4 permeation may include blocking of the intercellular spaces by aloe components (e.g. large polysaccharides) at higher concentrations or chemical interaction (e.g. complex formation) between aloe components and the FD4. Furthermore, the lack of aloverose in A. ferox gel $(6,10)$ may be the reason for its relatively small effect on FD4 permeation across the RPMI 2650 cell line. As mentioned before, aloverose is one of the bioactive constituents in $A$. vera gel (32) that may be predominantly responsible for modulation of tight junctions. These results for A. ferox gel across the nasal epithelial cell layers are similar to the results previously found across excised rat intestinal tissues and excised human skin tissues (6). Since FD4 is a macromolecular compound that is not normally transported by transcellular diffusion, the increase in permeation of FD4 that was observed in the presence of aloe materials indicated enhancement of paracellular movement possibly due to tight junction modulation. Tight junction modulation in intestinal epithelial cell monolayers was previously shown for A. vera gel (33). The higher effect of the A. muth-muth on FD4 permeation compared to the other aloe gel materials can possibly be related to the higher aloverose content as compared to that of $A$. vera gel and $A$. ferox gel, but this requires more research to be conclusive.

With regards to the aloe whole leaf extracts, the results found in the RPMI 2650 cell model are in line with previously published data on $A$. vera that increased paracellular permeation of insulin in a concentration dependent manner across human intestinal epithelial cell monolayers in vitro (2). A. vera whole leaf material showed in general the highest effect on FD4 permeation across the RPMI 2650 epithelial cell layers.
The considerable higher increase in FD4 permeation obtained in the excised sheep nasal mucosa as compared to the RPMI 2650 cell line for A. vera gel may be attributed to the differences in these two models. The RPMI 2650 cell line grows in multi-layers, whereas the sheep nasal mucosa has a single layer of epithelial cells (also indicated in the histology results above). A higher effect was observed in the excised tissue model with a single layer of epithelial cells.

The cytotoxic effects of $A$. vera gel that were found in vitro are similar to those previously found in Caco-2 cells (8), and in HeLa, HepG2 and SY-5Y cells (35). One explanation for the higher cytotoxic nature of the $A$. vera gel as compared to the $A$. vera whole leaf extract is the higher viscosity of the gel suspensions. The higher viscosity suspensions may have influenced the oxygen exchange and diffusion through the growth medium and prevented the cells from receiving sufficient quantities of oxygen. The in vitro results indicated that A. muthmuth leaf materials are safe to be used at concentrations where they are effective as functional excipients and/or bioenhancers, and that their increases on FD4 permeation (Figures 1 \& 2) can be credited to permeation enhancing effects and not tissue damage.

\section{Conclusion}

This study is one of the first to show the drug absorption enhancement potential of the gel and whole leaf extracts from different selected aloe species across the nasal epithelium. In general, A. vera gel increased paracellular permeation of a macromolecular compound across nasal epithelial models in a concentration dependent manner, which is in coherence to most previous findings across other mucosal surfaces (e.g. intestinal epithelium). However, the high viscosity of $A$. vera gel may have contributed to delayed permeation time, physical blockade of intercellular spaces and/or chemical interactions, which may also have occurred between phytochemicals in the $A$. vera gel and the permeate. This would explain the slight reduction in FD4 permeation in the RPMI 2650 cell model at the highest concentration as well as relatively high degree of deviation in the sheep nasal mucosa. A. 
vera whole leaf extract, on the other hand, had mediated a significant increase in paracellular transport, while both A. ferox gel and whole leaf extract showed enhancement of paracellular permeation in an inverse bell-shaped curve. Further studies would be needed with an extended concentration range to determine the trend of the permeation as a function of concentration.

Aloe muth-muth, a hybrid aloe species cultivated through forced pollination between $A$. vera and A. ferox, was also tested for its ability to enhance drug permeation across nasal epithelial membranes. Both $A$. muth-muth gel and whole leaf extract increased paracellular permeation of FD4 in a concentration dependent manner. The cytotoxicity of the A. muth-muth gel and whole leaf extract materials was mild and the neutral red experimental results were supported by the histological results, which indicated an absence of tissue damage.

The experimental results showed a relatively high potential for use of $A$. muth-muth gel and/or whole leaf extract in nasal dosage forms as functional excipients to enhance the bioavailability of certain drugs via tight junction modulation, but this should first be investigated with in vivo models to determine the clinical significance of their absorption enhancing effects. The experimental results also indicated that $A$. muth-muth gel or whole leaf extract have no damaging effects on the excised epithelial tissues.

\section{Acknowledgments}

The authors would like to thank Mr. Jaap and Hannes Viljoen of Rooiklip Nursery (Swellendam, South Africa) for the cultivation and provision of Aloe muth-muth materials.

\section{Authors' contributions}

JHH, JDS and AFK conceptualized and provided funding for the study. WG conducted and interpreted the permeation studies and results as well as composed the initial draft of the manuscript. HS conducted and interpreted toxicity and histology studies and data. CW provided necessary equipment and expert opinion on histological studies and data. All authors contributed to reading, interpreting, editing and confirmed the last edition of the manuscript for publication.

\section{Conflict of interests}

The authors declare no conflict of interest.

\section{Ethical considerations}

The research committee of Pharmacen, North-West University, South Africa approved the protocol for the study. Ethics approval for use of the excised sheep nasal tissue was obtained from Animal Research Ethics Committee (AnimCare) of the North-West University, South Africa (NWU-00285-17-A5) as a category 0 study (i.e. use of tissue from already dead animals, which in this case was from sheep slaughtered at an abattoir for meat production).

\section{Funding/Support}

This research was funded by the National Research Foundation (NRF) of South Africa (grant numbers 118418, 77287 and 98939). The funders had no role in the design of the study; in the collection, analyses, or interpretation of data; in the writing of the manuscript, or in the decision to publish the results.

\section{References}

1. Brandin H, Viitanen E, Myrberg O, Arvidsson AK. Effects of herbal medicinal products and food supplements on induction of CYP1A2, CYP3A4 and MDR1 in the human colon carcinoma cell line LS180. Phytother Res. 2007;21:239-244. doi: 10.1002/ptr.2057.

2. Chen W, Lu Z, Viljoen A, Hamman J. Intestinal drug transport enhancement by Aloe vera. Planta Med. 2009;75:578-595. doi: 10.1055/s-0029-1185341.

3. Vinson JA, $\mathrm{Al}$ Kharrat $\mathrm{H}$, Andreoli L. Effect of Aloe vera preparations on the human bioavailability of vitamins C and E. Phytomed. 2005;12:760-765. doi: 10.1016/j. phymed.2003.12.013.

4. Ojewole E, Mackraj I, Akhundov K, Hamman J, Viljoen A, Olivier E, et al. Investigating the effect of Aloe vera gel on the buccal permeability of didanosine. Planta Med. 2012;78:354-361. doi: 10.1055/s-0031-1280431.

5. Cole L, Heard C. Skin permeation enhancement potential of Aloe vera and a proposed mechanism of action based upon size exclusion and pull effect. Int J Pharm. 2007;333:10-16. doi: 10.1016/j.ijpharm.2006.09.047.

6. Fox LT, Gerber M, Du Preez JL, Du Plessis J, Hamman JH. Skin permeation enhancement effects of the gel and whole-leaf materials of Aloe vera, Aloe marlothii and Aloe ferox. J Pharm Pharmacol. 2014;67:96-106. doi: 10.1111/ jphp.12311.

7. Beneke C, Viljoen A, Hamman J. Modulation of drug efflux by aloe materials: An in vitro investigation across rat intestinal tissue. Pharmacogn Mag. 2013;9(36):S44-S48. doi: $10.4103 / 0973-1296.117864$.

8. Djuv A, Nilsen OG. Caco-2 cell methodology and inhibition of the P-glycoprotein transport of digoxin by Aloe vera juice. Phytother Res. 2008;22:1623-1628. doi: 10.1002/ptr.2536.

9. Chen W, Van Wyk BE, Vermaak I, Viljoen AM. Cape aloes - A review of the phytochemistry, pharmacology and commercialisation of Aloe ferox. Phytochem Lett. 2012;5:112. doi: 10.1016/j.phytol.2011.09.001.

10. Beneke C, Viljoen A, Hamman JH. In vitro drug absorption enhancement effects of Aloe vera and Aloe ferox. Sci Pharm. 2012;80:475-486. doi: 10.3797/scipharm.1202-10.

11. Kreft ME, Jerman UD, Lasič E, Rižner TL, Hevir-Kene N, Peternel L, et al. The characterization of the human nasal epithelial cell line RPMI 2650 under different culture conditions and their optimization for an appropriate in vitro nasal model. Pharm Res. 2015;32:665-679. doi: 10.1007/ s11095-014-1494-0.

12. Lungare S, Bowen J, Badhan R. Development and 
evaluation of a novel intranasal spray for the delivery of amantadine. J Pharm Sci. 2016;105:1209-1220. doi: 10.1016/j.xphs.2015.12.016.

13. Wengst A, Reichl S. RPMI 2650 epithelial model and threedimensional reconstructed human nasal mucosa as in vitro models for nasal permeation studies. Eur J Pharm Biopharm. 2010;74:290-297. doi: 10.1016/j.ejpb.2009.08.008.

14. Bai S, Yang T, Abbruscato TJ, Ahsan F. Evaluation of human nasal RPMI 2650 cells grown at an air-liquid interface as a model for nasal drug transport studies. J Pharm Sci. 2008;97(3):1165-1178. doi: 10.1002/jps.21031.

15. Dolberg AM, Reichl S. Activity of multidrug resistanceassociated proteins 1-5 (MRP1-5) in the RPMI 2650 cell line and explants of human nasal turbinate. Mol Pharm. 2017;14:1577-1590. doi: 10.1021/acs. molpharmaceut.6b00838.

16. Reichl S, Becker K. Cultivation of RPMI 2650 cells as an in vitro model for human transmucosal nasal drug absorption studies: optimization of selected culture conditions. J Pharm Pharmacol. 2012;64:1621-1630. doi: 10.1111/j.20427158.2012.01540.x.

17. Schmidt MC, Peter H, Lang SR, Ditzinger G, Merkle HP. In vitro cell models to study nasal mucosal permeability and metabolism. Adv Drug Deliv Rev. 1998;29:51-79. doi: 10.1016/S0169-409X(97)00061-6.

18. Soane RJ, Hinchcliffe M, Davis SS, Illum L. Clearance characteristics of chitosan based formulations in the sheep nasal cavity. Int J Pharm. 2001;217:183-191. doi: 10.1016/ S0378-5173(01)00602-0.

19. Boudreau MD, Beland FA. An evaluation of the biological and toxicological properties of Aloe barbadensis (Miller), Aloe vera. J Environ Sci Health C. 2006;24:103-154. doi: 10.1080/10590500600614303.

20. O'Brien C, Van Wyk BE, Van Heerden FR. Physical and chemical characteristics of Aloe ferox leaf gel. S Afr J Bot. 2011;77:988-995.

21. Krebs-Ringer Bicarbonate Buffer. Sigma-Aldrich. 2007. https://www.sigmaaldrich.com/content/dam/sigmaaldrich/docs/Sigma/Product_Information_Sheet/1/ k4002pis.pdf. Accessed 4 March 2019.

22. Jiao P, Jia Q, Randel G, Diehl B, Weaver S, Milligan G. Quantitative ${ }^{1} \mathrm{H}$-NMR spectrometry method for quality control of Aloe vera products. J AOAC Int. 2010;93(3):842848.

23. Nakamura K, Maitani Y, Takayama K. The enhancing effect of nasal absorption of FITC-dextran 4,400 by $\beta$-sitosterol $\beta$-D-glucoside in rabbits. J Control Release. 2002;79:147155. doi: 10.1016/S0168-3659(01)00540-5.

24. Dolberg AM, Reichl S. Expression of P-glycoprotein in excised human nasal mucosa and optimized models of RPMI 2650 cells. Int J Pharm. 2016;508:22-33. doi: 10.1016/j.ijpharm.2016.05.010.

25. Chung FY, Donovan MD. Nasal pre-systemic metabolism of peptide drugs: Substance P metabolism in the sheep nasal cavity. Int J Pharm. 1996;128:229-37. doi: 10.1016/03785173(95)04313-6.

26. Pund S, Rave G, Borade G. Exvivo permeation characteristics of venlafaxine through sheep nasal mucosa. Eur J Pharm Sci. 2013;48:195-201. doi: 10.1016/j.ejps.2012.10.029.

27. Rahtnam G, Narayanan N, Ilavarasan R. Carbopol-based gels for nasal delivery of progesterone. AAPS Pharm Sci Tech. 2008;9(4):1078-82. doi: 10.1208/s12249-008-9144-7.

28. Gerber W, Hamman JH, Steyn JD. Excipient-drug pharmacokinetic interactions: Effect of disintegrants on efflux across excised pig intestinal tissues. J Food Drug Anal. 2018;26:S115-24. doi: 10.1016/j.jfda.2018.01.007.

29. Pozzoli M, Ong HX, Morgan L, Sukkar M, Traini D, Young PM, et al. Application of RPMI 2650 nasal cell model to a 3D printed apparatus for the testing of drug deposition and permeation of nasal products. Eur J Pharm Biopharm. 2016;107:223-33. doi: 10.1016/j.ejpb.2016.07.010.

30. Bruggisser R, Von Daeniken K, Jundt G, Schaffner $\mathrm{W}$, Tullber-Reinet $\mathrm{H}$. Interference of plant extract, phytoestrogens and antioxidants with the MTT tetrazolium assay. Planta Med. 2002;68:445-448. doi: 10.1055/s-200232073.

31. Marriott C. Rheology. In: Aulton ME, edr. Aulton's pharmaceutics the design and manufacture of medicines. New York: Churchill Livingstone; 2007. p. 42-58.

32. Sánchez-Machado DI, López-Cervantes J, Sendón R, Sanches-Silva A. Aloe vera: Ancient knowledge with new frontiers. Trends Food Sci Technol. 2017;61:94-102. doi: 10.1016/j.tifs.2016.12.005.

33. Haasbroek A, Willers C, Glyn M, Du Plessis L, Hamman J. Intestinal drug absorption enhancement by Aloe vera gel and whole leaf extract: In vitro investigations into the mechanisms of action. Pharmaceutics. 2019;11(1):36. doi: 10.3390/pharmaceutics11010036.

34. López-García J, Lehocký M, Humpolíček P, Sáha P. HaCat keratinocytes response on antimicrobial atelocollagen substrates: Extent of cytotoxicity, cell viability and proliferation. J Funct Biomater. 2014;5:43-57. doi: 10.3390/ jfb5020043.

35. Du Plessis LH, Hamman JH. In vitro evaluation of the cytotoxic and apoptogenic properties of aloe leaf and gel materials. Drug Chem Toxicol. 2014;37(2):169-177. doi: 10.3109/01480545.2013.834356. 